\title{
COLONIALIDADADE DO SABER NO ENSINO DA EDUCAÇÃO BÁSICA: RESISTÊNCIA OU REPRODUÇÃO DO EUROCENTRISMO?
}

\author{
Dina Maria Martins Ferreira* \\ Julianne Rodrigues Pita**
}

\section{Resumo}

Este trabalho busca problematizar o ensino de literatura na Educação Básica brasileira. Levantam-se conceitos de colonialidade do saber e de colonialidade do poder para explicar como o eurocentrismo ainda se faz presente no discurso da Escola Brasileira, aventando sobre a possibilidade de resistência ou não ao colonizador. Trata-se de uma pesquisa que dialoga com teóricos do ensino e do pensamento descolonial.

\section{Palavras-chave}

Colonialidade do saber e do poder. Reprodução ou resistência. Ensino. Literatura.

\section{1) Introdução}

Ao tomarmos conhecimento sobre Epistemologias do sul (SANTOS; MENEZES, 2011), como docentes, nos vimos diante de problemáticas a respeito do ensino de literatura na Educação Básica da Escola Brasileira (BOSI, 1992) ou seja, como a colonialidade (SANTOS; SIVERES, 2013) ainda atravessa textos em livros didáticos. No Sul se circunscrevem epistemologias que ainda recebem influência da ala colonizadora, o Norte. Importante observar que territórios, nações e culturas não se enquadram na perspectiva do Sul e do Norte por linhas geográficas, e sim por territórios simbólicos, e respectiva pertença identitária (VATTIMO, s/d), separando nações pelo critério simbólico-cultural (HAESBAERT, 2004) no que tange a prerrogativas dos que são considerados subdesenvolvidos em relação aos ditos modernos e adiantados (CEREJA, 2009).

\footnotetext{
* $2^{\mathrm{o}}$ pós-doutorado, em Ciências Sociais, pela Université Paris V, Sorbonne, em co-tutoria em Estudos da Linguagem, pelo Instituto de Estudos da Linguagem, Unicamp (2009-2010); $1^{\circ}$ pós-doutorado em Pragmática, pelo Instituto de Estudos da Linguagem, Unicamp (2002-2003); doutorado em Linguística pela Universidade Federal do Rio de Janeiro (1995); mestrado em Letras pela Pontifícia Universidade Católica do Rio de Janeiro (1988). Pesquisadora do Centro de Atualidades e Cotidiano da Université Paris V, Sorbonne. Professora e pesquisadora do Programa de Pós-Graduação em Linguística Aplicada, Universidade Estadual do Ceará. Autora de 4 livros, organização de 5 livros, capítulo de livros, artigos nacionais e internacionais. dinaferreira@terra.com.br

** Mestranda do Programa de Pós-Graduação em Linguística Aplicada, Universidade Estadual do Ceará. juliannepita95@gmail.com
} 
A noção de territorialidade (HAESBAERT, 2004) traz à tona a identidade de pertencimento, já que é constituído por representações sociais, políticas, econômicas e culturais. Haesbaert (2004) nos oferece um tratamento de território pela vertente cultural ou como chama de "simbólico-cultural: [que] prioriza a dimensão simbólica em que o território é visto, sobretudo, como o produto da apropriação/valorização simbólica de um grupo em relação ao seu espaço vivido" (2004, p. 40). Ou melhor, a dimensão simbólica habita um espaço social organizando-se pela historialização e geograficidade. Na historialização, os territórios colonizados alimentam o imaginário-cultural: "na dimensão espacial das relações econômicas, o território [é visto] como fonte de recursos e/ou incorporado no embate entre classes sociais e na relação capital-trabalho" (2004, p. 40). Além disso, pelo conceito de território simbólico, estaríamos, então, em espaço de performativos valorativos, que constrói a pertença identitária (VATTIMO, s/d). Nesse universo simbólico-identitário, as narrativas históricas se fazem presentes, tanto pela historicidade quanto pela historialidade. No âmbito da historicidade, há um motivo para que o pertencimento se manifeste, além da(s) história(s) em que o motivo se circunscreve. No âmbito da historialidade, o efeito identitário da narrativa histórica provoca e acolhe a posição de pertença; pertença a um grupo, a uma nação, a uma região. A historialização seria, então, "um processo objetivo no qual estamos inseridos [...] um modo de estarmos conscientes dessa pertença" (s/d, p.11). No caso de nosso trabalho, inclusive, pelo imaginário popular e por experiências empíricas, indagamos se o território brasileiro e a identidade de brasilidade tem consciência desta pertença ao Sul dos subdesenvolvidos.

Mesmo sem uma consciência explícita, o senso comum aloca os países e culturas latino-americanas e africanas na ala Sul dos subdesenvolvidos e na ala dos modernos a Europa e os Estados Unidos. Criam-se, então, dicotomias tais como colonizador/colonizado, dominantes/dominados, violentos/submissos, entre outras. No entanto, estas dicotomias dependem do contexto e do lugar de onde se fala, ou melhor, na época das conquistas, senão até hoje. Pelo folclore oral brasileiro, Portugal em relação a outros países da Europa também é considerado subdesenvolvido, o que leva a brincadeira derrisiva de que Portugal pertence ao norte da África. Já em outro exemplo, Austrália em relação ao Brasil apontaria para o moderno e o atrasado, respectivamente, e, em relação aos Estados Unidos, Austrália seria um território subdesenvolvido ${ }^{1}$.

\footnotetext{
${ }^{1}$ Estes exemplos, apesar de já pertencerem ao folclore oral brasileiro, já é base de discussão em áreas acadêmicas, ainda sem um estudo local e estatístico.
} 
No caso de nossa argumentação, adotamos os seguintes territórios simbólicos (HAESBAERT, 2004), Europa (Portugal) versus Brasil, em que o eurocentrismo dita normas e regulamentos culturais e epistemológicos, constituindo o que chamamos de colonialismo. É neste percurso que se contextualiza o ensino de literatura.

Assim, com esta contextualização, abordaremos como os livros didáticos separam a língua portuguesa de literatura, como se a literatura não fosse construída dentro da língua. E também discutiremos sobre colonialidade, destacando o poder e o saber, demonstrando que esta é continuação daquela. Em seguida, examinaremos o primeiro documento, creditado à literatura, a carta de Pero Vaz de Caminha, que exemplifica a colonialidade.

Sem nenhuma pretensão de análise dos livros didáticos, este estudo delineia-se mais como um ensaio em que o chamamento à reflexão de busca de resistência se faz a "mola propulsora".

\title{
2) Língua e literatura: dissociação
}

Como propulsor da construção de leitores dentro da Educação Básica, a literatura surge como uma proposta necessária para a análise e compreensão de períodos históricos e sociedades através das suas produções escritas e dos seus contextos de produção, tornando-se um sistema formado por denominadores comuns, que:

\begin{abstract}
são, além das características internas como (língua, temas e imagens), certos elementos da natureza social e psíquica, embora literariamente organizados, que se manifestam historicamente e fazem da literatura aspecto orgânico. Entre eles se distinguem: a existência de um conjunto de produtores literários, mais ou menos conscientes de seu papel; um conjunto de receptores, formando os diferentes tipos de público, sem os quais a obra não vive; um mecanismo transmissor (de modo geral, uma linguagem, traduzida em estilos), que liga uns a outros (CANDIDO, 2000, p. 23).
\end{abstract}

Literatura seria a linguagem fundamentada nas relações humanas e nos contextos sociais, em que a tríade, produtor-receptor-mecanismo transmissor, se desenvolve, ou seja, "as veleidades mais profundas dos indivíduos se transformam em elementos de contato entre os homens, e de interpretação de diferentes realidades" (CANDIDO, 2000, p. 23). Por este viés, podemos compreender a literatura como formadora de processos históricos e sociais. Em contexto mais reducionista - e na prática educativa no Ensino 
Básico -, tem se observado o estudo da literatura sob uma escala hierárquica: de um lado, uma reprodução de dogmas relativos ao prestígio literário de cidadãos ditos cultos; e, de outro, a excludência de pessoas que não desenvolveram a competência leitora da dita literatura clássica.

E a problemática ainda continua, quando se verifica que os estudos literários, em âmbito escolar, por uma via, e o estudo instituído da gramática e seus usos, por outra, causaram, e ainda causam, uma visão separatista entre o ensino de língua portuguesa e literatura provocando uma dissociação entre ambas. Essa dissociação não deveria acontecer visto que estão interligadas diretamente pelo código de comunicação. Essa visão dúbia foi herança da Lei de Diretrizes e Bases de 1971 como bem esclarece Cereja (2009) ao elucidar que:

Os Parâmetros Curriculares Nacionais - Ensino Médio (1999:53) - ao discutirem os problemas do ensino de língua portuguesa, fazem referência à dicotomia em relação à disciplina existente na LDB 5.692/71, que a dividia em 'Língua e Literatura (com ênfase na literatura brasileira) $(2009$, p. 54).

Como exemplo deste separatismo, temos a escolha dos livros didáticos de uso na Rede Estadual de Ensino Médio em Fortaleza², constituída por um universo de 157 escolas. A adoção destes livros foi realizada no ano de 2017 através do Plano Nacional do Livro Didático (PNLD) ${ }^{3}$ e está validada para o triênio - 2018, 2019 e $2020^{4}$ :

\begin{tabular}{|c|c|c|}
\hline Coleção $1^{8} 0$ p̧̧ão & Descrição & Qt. pedida \\
\hline $0081 P 18013$ & PORTUGLÊS CONTEMPORÂNEO: DIÁLOGO, REFLEXÃO E USO & 61 \\
\hline $0175 \mathrm{P} 18013$ & PORTUGUÊS ? CONTEXTO, INTERLOCUČ̃ÃO E SENTIDO & 21 \\
\hline $0194 \mathrm{P} 18013$ & SE LIGA NA LINNGUA: LITERATURA, PRODUCC:ÃO DE TEXTO, LINGUAGEM & 19 \\
\hline $0080 P 18013$ & PORTUGUÊS: TRILHAS E TRAMAS & 17 \\
\hline $0135 \mathrm{P} 18013$ & NOVAS PALAVRAS & 15 \\
\hline $0063 P 18013$ & SER PROTAGONISTA LINGGUA PORTUGUESA & 13 \\
\hline $0144 \mathrm{P} 18013$ & ESFERAS DAS LINGUAGENS & 5 \\
\hline $0019+18013$ & LÍNGUA HOKIUGUUSA: LINGUAGGM E INIEKAC:Ã̃U & 3 \\
\hline $0106 \mathrm{P} 18013$ & PORTUGUÊS: LINGUAE CULTURA & 2 \\
\hline $0112 \mathrm{P} 18013$ & VEREDAS DA PALAVRA & 1 \\
\hline
\end{tabular}

\footnotetext{
${ }^{2}$ Nosso exemplo focou o território do Estado do Ceará, devido a nossa contextualização a este lócus de pesquisa, tanto no que se refere à prática docente, quanto ao acompanhamento em sala de aula da prática docente de outros professores.

${ }^{3}$ Disponível em: portal.mec.gov.br/busca-geral/318-programas-e-acoes.../pnld.../12391-pnld. Acesso em 13 de mar. de 2019.

4 Disponível em: https://www.seduc.ce.gov.br/.../8477-coordenacao-estadual-dos-programas-do-livrodidatico. Acesso em 15 de fev. de 2019. Ou ver Brasil, Secretaria da Educação Básica, 2015.
} 
Na maioria destes livros didáticos, não há uma relação efetiva entre o estudo da língua materna e o estudo de literatura. Os textos literários são instrumentos para análises gramaticais, e, quando muito, são utilizados como molde comprobatório para contextualizar um período literário e suas características:

Como se vê, o texto, que deveria ser o centro das atividades de uma aula de literatura, espaço aberto para a negociação de diferentes leituras e construções de sentido, geralmente acaba por assumir um papel periférico nessa sequência. Por extensão, na prática, o ensino de literatura no ensino médio não tem alcançado os objetivos propostos pelos programas escolares - entre outros, o desenvolvimento de habilidades leitoras dos alunos - e tem-se limitado a promover a apropriação de um discurso didático sobre a literatura, produzido e representado, em primeira instância, pelo professor e, em segunda instância, produzido socialmente por diferentes agentes: pelo livro didático, pelos programas universitários, pelas referências historiográficas disponíveis para consulta de professores, pelo programa vestibular de algumas universidades, por alguns sites da Internet, etc (CEREJA, 2009, p. 57).

Entretanto, essa visão dissociada entre língua e literatura vem sofrendo alterações, principalmente no que diz respeito aos documentos norteadores do ensino escolar básico. Como exemplo, temos a última edição da Base Nacional Comum Curricular (BNCC):

Durante toda a Educação Básica, deve-se favorecer a formação literária, de modo a garantir a continuidade do letramento literário, iniciado na Educação Infantil. Esse tipo de letramento é entendido como o processo de apropriação da literatura como linguagem que oferece uma experiência estética, bem como a ampliação gradativa das referências culturais compartilhadas nas comunidades de leitores que se constituem na escola. Pela literatura, constituem-se subjetividades, expressam-se sentimentos, desejos, emoções, de um modo particular, com uso diversificado de recursos expressivos. Nesse processo, a formação de leitores literários envolve reflexão sobre a linguagem, o que implica o reconhecimento de procedimentos de elaboração textual e a consciência das escolhas estéticas envolvidas na construção dos textos (BRASIL, 2003, p. 96; BRASIL, 2015).

Mesmo que se considere o estudo da literatura como formador de indivíduos cultos e letrados, percebemos a presença constante de textos canônicos, muitas vezes de linguagem de difícil compreensão para alunos do Ensino Médio. Estes textos e algumas obras, por vezes, se distanciam da realidade e da linguagem atual, dificultando o interesse pela leitura, que é cada dia mais escasso, inclusive devido ao desenvolvimento das novas tecnologias e à quantidade de informações que rodeiam o cotidiano contemporâneo. Nesta 
conjuntura de tecnologias e excesso de informações, emerge um caminho oposto desejado em detrimento da expansão da leitura que deveria ser alimentada durante as aulas de literatura. Mas, mesmo diante deste caminho adverso, somado a ditas "consultas e pesquisas enfadonhas em dicionários", ainda "passear" pelo mundo literário é, aos "olhos do outro", subir um patamar na hierarquia cultural.

Outro ponto propagador da conceituação de que detentor da cultura é aquele que reverencia a leitura das belas letras é a devoção às literaturas europeias. Entretanto, temos aqui um fator que vai além do campo da análise literária, pois neste aspecto não se acarreta apenas a ótica da leitura canônica, mas, sim, de que ser culto não é apenas ler e compreender textos canônicos da literatura brasileira, mas, também ler o que vem diretamente do continente colonizador. E no que tange a leituras territorializadas em relação hierárquica de colonizador/colonizado, surge a problemática tanto de ordem literária quanto sociológica, pois esta obrigatoriedade de conteúdos europeus no ensino brasileiro, como fator de status, em detrimento das literaturas brasileira e africana ${ }^{5}$, pode causar desinteresse do aluno pela leitura. Ou melhor, o aluno se desinteressa da leitura de textos que não lhe são palatáveis, ou seja, não fazem parte de sua perspectiva de linguagem, nem de sua realidade e posição na sociedade. Tal habitus ${ }^{6}$ (BOURDIEU, 2011) entra em contradição, mais uma vez, com o que é apresentado pela BNCC, quando esta propõe o tipo de literatura que deve ser promovida e estudada em contexto escolar. A Base Nacional Comum Curricular, numa visão desafiadora, estimula a escolha dos livros que privilegie autores e obras pertencentes ao seu contexto local e regional:

É importante também que os/as estudantes sejam apresentados/as a autores das literaturas africanas de língua portuguesa. Seria desejável, ainda, que se conseguisse oportunizar o contato com algumas obras literárias de outros países - por exemplo, de autores latino-americanos, pouco lidos entre nós, de autores da tradição ou da literatura moderna de outros continentes - dentro de projetos de leitura significativos (BRASIL, 2003, p. 508).

\footnotetext{
${ }^{5} \mathrm{O}$ ensino de literaturas africanas é pautado na Lei $\mathrm{n}^{\circ} 10.639$ promulgada no dia 9 de janeiro de 2003 que altera a Lei de Diretrizes e Bases da Educação Nacional (LDB - Lei 9.394/96) tornando obrigatório o estudo da história e cultura afro-brasileira e africana nos estabelecimentos de Ensino Fundamental e Médio. Esta lei busca resgatar a contribuição do povo negro e os conteúdos referentes a ela devem ser ministrados em todo o currículo escolar, em especial, nas áreas de Educação Artística e de Literatura e Histórias Brasileiras, como se encontra descrito no próprio corpo do texto da lei. Esta lei ainda encontra limitações e resistência nas práticas escolares do ensino de literatura.

${ }^{6}$ Habitus, segundo Bourdieu (2011), é um conjunto de normas e comportamentos que caracterizam determinado campo social.
} 
Diante da amplitude da literatura no componente curricular, tornar-se relevante o estudo de seu lócus de atuação - de onde emerge a colonialidade do saber ${ }^{7}$.

\section{3) Pensamento colonial e eurocentrismo: resistência ou reprodução}

Pensar em colonialidade do saber, inclusive no ensino brasileiro, é nos deter na problemática da cultura latino-americana e do eurocentrismo. Autores do chamado pensamento descolonial descortinam tal problemática, que ainda é pouco discutida no âmbito escolar brasileiro, especificadamente no estudo das escolas literárias.

Tomando como ponto de partida o processo de colonização da América, o sociólogo peruano Aníbal Quijano (2005) se propõe a analisar e provocar discussões acerca da produção do conhecimento na América Latina e de como ela é, ainda, extremamente permeada por influências europeias. Suas reflexões nos levam a conceitos sobre o continente americano, em específico sobre a América do Sul, em que se elucidam processos de colonização que se caracterizaram não só pela retirada de bens materiais, mas também pela imposição cultural e pela negação da identidade - esta permeada por dogmas e verdades construídos sobre nós e não por nós.

Já o venezuelano Edgardo Lander (2005) explicita como se originou o pensamento descolonial: “Com o início do colonialismo, na América inicia-se não apenas a organização colonial do mundo, mas - simultaneamente - a constituição colonial dos saberes, das linguagens, da memória e do imaginário" (2005, p. 10). Essa constituição de saberes aprisionou a América Latina a concepções criadas pela cultura europeia colonizadora, que normatiza como "certo" aqueles que adotam as normas dos colonizadores europeus, e o "errado", os que querem mudar o processo hierarquizador, que se efetiva desde os territórios conquistados pelas grandes navegações, através da cultura e costumes dos povos conquistados, considerados como subdesenvolvidos até os dias de hoje. O fenômeno da colonialidade, até os dias atuais, afeta o nosso modo de pensar e agir em sociedade, interferindo, indiretamente, nos âmbitos de aprendizagem, em específico, na escola.

O habitus colonial, no campo da educação básica, coloca a Escola como uma das instituições afetadas pela doutrinação colonial, em detrimento do esquecimento da nossa

\footnotetext{
${ }^{7}$ Outros elementos também são relevantes, mas não fazem parte do momento deste estudo, tais como, o papel do professor, a escolha dos livros didáticos e os documentos reguladores do ensino.
} 
literatura regional e latino-americana. Parece estarmos, desde o início da nossa história, pré-determinados a seguir os ditames europeus em diversos aspectos, inclusive na constituição do nosso processo educacional. No ensino de língua materna e literatura, o que se vê é a presença constante dos nossos colonizadores com sua herança cultural, ou seja, uma:

[...] construção eurocêntrica, que pensa e organiza a totalidade do tempo e do espaço para toda a humanidade do ponto de vista de sua própria experiência, colocando sua especificidade histórico-cultural como padrão de referência superior e universal (LANDER, 2005, p. 13).

Ou melhor, no nosso contexto de ensino de língua materna e literatura, verificase uma visão passiva, em que, muitas vezes, reproduzimos as prerrogativas eurocêntricas, alheios à nossa realidade e distantes da nossa compreensão - sobram textos para explicar "verdades europeias", mas falta contexto para entender criticamente sua postura colonial.

Se as estruturas sociais no Brasil, no que tange ao ensino escolar, ainda reproduzem as prerrogativas eurocêntricas, não podemos deixar de levantar a questão do conservadorismo (BOURDIEU; PASSERON, 2008), em geral, que atravessa o sistema de ensino. Ou seja, o eurocentrismo não seria apenas uma força de imposição colonial e histórica, mas também a própria representação do "conservadorismo do sistema". Se aventarmos o conceito de educação, ela não se refere apenas a questões de conhecimento, mas também a comportamentos restritivos civilizatórios. Por exemplo, uma pessoa educada não seria apenas ou só uma pessoa com determinado grau de instrução e de leituras, mas também uma pessoa adequada a normas e bons costumes - dir-se-ia uma pessoa civilizada. Não é à toa que cultura e civilização se imbricam em várias patamares conceituais $^{8}$. Bourdieu e Passeron (2008) nos auxilia na argumentação problemática sobre reprodução do sistema de ensino9

[...] Para mim ainda hoje [1999] é surpreendente, como foi naquela época [1969] que o fato de dizer que uma instância como o sistema de ensino contribui para conservar as estruturas sociais, ou dizer que as estruturas tendem a se conservar ou se manter - o que é uma constatação -, é surpreendente que esta constatação seja percebida como uma declaração conservadora. Basta pensarmos um pouco para percebermos

\footnotetext{
${ }^{8}$ Para maiores detalhes sobre a junção e separação conceitual entre cultura e civilização ver Eagleton (2003).

${ }^{9} \mathrm{Na}$ edição brasileira de 2008, na Apresentação da obra, feita Nadia Gaiofatto Gonçalvez, esta cita a fala de Bourdieu em entrevista concedida a Maria Andréa Loyola em 1999, realizada 30 anos depois da publicação do original em francês.
} 
que o mesmo enunciado sobre a existência de mecanismos de conservação pode ter um caráter revolucionário.[...] Quando você diz as coisas são assim, pensam que você está dizendo as coisas devem ser assim, ou é bom que as coisas sejam dessa forma, ou ainda o contrário, as coisas não devem mais ser assim [...]. Continuo a pensar que o sistema de ensino contribui para conservar. Insisto sobre o que contribui, o que é muito importante aqui. Não digo conserva, reproduz, digo contribui para conservar (grifos do autor) - (2008, p. 13-15).

No entanto, o embate sobre a influência da cultura europeia avança para nossa contemporaneidade pelas vozes dos pensadores descoloniais ${ }^{10}$. Em reflexões sobre o Brasil, Sérgio Buarque de Holanda, um dos três grandes intérpretes do Brasil, ao lado de Caio Prado Junior e Gilberto Freyre que formaram a chamada geração de 30, afirma que:

A tentativa de implantação da cultura europeia em extenso território, dotado de condições naturais, se não adversas, largamente estranhas a sua tradição milenar, é nas origens da sociedade brasileira, o fato dominante e de mais ricas consequências trazendo de países distantes nossas formas de convívio, nossas instituições, nossas ideias, e timbrando em manter tudo isso em ambiente muitas vezes desfavorável e hostil, somos ainda uns desterrados em nossa terra (HOLANDA, 2013, p. 31).

De nossa perspectiva, o que compreendemos como "tradicionalismo no ensino sistemático das escolas literárias" é uma das consequências dessa implantação cultural que prioriza a necessidade de entender o que é a sociedade europeia e sua produção escrita, para depois compreendermos o que aqui se faz. Essa visão eurocêntrica de mundo é basilar para esclarecer alguns fatores causadores desta imposição cultural, que, de tão naturalizada, nos faz esquecer o preço que pagamos pela sua efetividade:

Ao nos reportamos à configuração do mundo ao final do século $\mathrm{XV}$, início do século XVI, quando encontramos uma Europa em que se destacam os países ibéricos, por terem retomado suas terras e mostrarem condições e ousadia para se aventurar por mares nunca dantes navegados. É verdade que Portugal e Espanha não estão sozinhos nessa empreitada. A Itália tem também um destaque, mas seu acesso garantido ao Mediterrâneo tira-a do centro das disputas pelo Atlântico. O mesmo não acontece a outros povos, como os holandeses. Assim também, França e Inglaterra, saídas de um século de guerras e tensões, compartilham do mesmo imaginário europeu ocidental, considerando-se o centro do universo, ao redor do qual tudo devia girar. Como não tinham as bênçãos do Papa, urgia que encontrassem outros

${ }^{10}$ Entre os muitos, citamos: Castro-Goméz, 2005; Dussel, 2005; Lander, 2005; Quijano, 2005; Santos e Menezes, 2011. 
meios de tirar proveito dessas descobertas que vinham fazendo os ibéricos (grifos do autor) - (AZIBEIRO, 2016, p. 2).

No contexto histórico e social dos períodos de exploração de novas terras, inicialmente realizada por Portugal e Espanha, cujos territórios mais tarde ganhariam o nome de América Latina, surgem novos conceitos sociais, tal como o sentido de modernidade. A dicotomia países modernos e países tradicionais sempre marcou a história da cultura ocidental, em que ganha notoriedade a cultura europeia e posteriormente a estadunidense. A grande contribuição dos pensadores da descolonialidade $^{11}$ é problematizar o conceito de modernidade que, na verdade, surge como fruto do processo de colonização, em que o colonizador dependia de um "outro", o seu contrário, o atraso. Emerge, então, a noção de América da perspectiva de que o atrasado precisava ser modernizado.

Dessa maneira, como bem defende o filósofo argentino Dussel (2005), a modernidade instituída por concepções eurocêntricas evidencia como moderno aquilo se prende e tem origem no continente europeu. Todo o resto, não pertencente a este contexto geográfico e simbólico, é considerado retrógrado, principalmente no que se refere ao que era produzido no período de colonização, pois os povos pobres e 'descobertos' necessitavam, mesmo que de maneira obrigatória e forçosa, a ver a luz da razão europeia, visão positivista que já circundava a formação de uma Europa Iluminista (segunda fase da constituição da modernidade, segundo este autor).

Dussel (2005) nos mostra também, de forma mais específica, dois conceitos do que seja a Modernidade: "O primeiro deles é eurocêntrico, provinciano, regional. A modernidade é uma emancipação, uma 'saída' da imaturidade por um esforço da razão como processo crítico, que proporciona à humanidade um novo desenvolvimento do ser humano" (2005, p. 27). Este primeiro conceito já é propagado pelas primeiras produções literárias registradas ${ }^{12}$ no período de descoberta do território brasileiro, ou seja, o europeu, o moderno, vem para desenvolver o pensamento crítico do índio. O segundo conceito é a:

'Modernidade', num sentido mundial, e consistiria em definir como determinação fundamental do mundo moderno o fato de ser (seus Estados, exércitos, economia, filosofia, etc.) "centro" da História

\footnotetext{
${ }^{11}$ Vide nota de rodapé 10.

${ }^{12}$ O Quinhentismo, no item Escola Literária Brasileira, é abordado como exemplo de produções literárias no primeiro período colonialista no Brasil.
} 
Mundial. Ou seja, empiricamente nunca houve História Mundial até 1492 (como data de início da operação do "Sistema-mundo"). Antes dessa data, os impérios ou sistemas culturais coexistiam entre si. Apenas com a expansão portuguesa desde o século $\mathrm{XV}$, que atinge o extremo oriente no século XVI, e com o descobrimento da América hispânica, todo o planeta se torna o 'lugar' de 'uma só' História Mundial [...] (2005, p. 29).

Constitui-se então, a partir desses dois conceitos de Modernidade, a premissa de que o 'centro' da História Mundial preconiza todas as outras culturas como periféricas em relação à cultura europeia. A modernidade hierarquizada e centralizada em contexto europeu, quando repetida sem filtros de criticidade, autoafirma a Europa como "detentora da civilização" e da "evolução social", anulando as demais culturas e consequenciando em um processo de "violência epistêmica" (CASTRO-GOMÉZ, 2005, p. 83) constituinte do perfil do cidadão latino-americano do século XIX, de acordo com os padrões da modernidade eurocêntrica.

A chegada dos portugueses, todavia, poderia ter servido de grande valia para o enriquecimento da diversidade cultural brasileira, mas o que ocorreu, em primazia, foi o surgimento da modernidade "como dispositivo que construía o 'outro' mediante uma lógica binária que reprimia as diferenças" (CASTRO-GOMÉZ, 2005, p. 80). Essa repressão às diferenças formulou um grande "abismo identitário" entre colonizador e colonizado, estabelecendo relações de poder entre as duas pontas:

O colonizado aparece assim como o 'outro' da razão, o que justifica o exercício de um poder disciplinar por parte do colonizador. A maldade, a barbárie e a incontinência são marcas 'identitárias' do colonizado, enquanto que a bondade, a civilização e a racionalidade são próprias do colonizador (CASTRO-GOMÉZ, 2005, p. 83).

Enfim, o colonizado, pelo viés de submissão, precisa de regras que o coloquem em nível adequado de convivência, de cultura e de conhecimento do colonizador, cujo uso de leis e de disciplina se faz instrumento para a sua redenção à ocidentalização europeia. O progresso surge então como produto da ideologia europeia, nos fazendo pressupor por que "jamais houve modernidade sem colonialidade" (SANTOS; SÍVERES, 2013, p. 125). 


\section{4) Colonialidade do poder e do saber}

É a partir desse processo de colonização cultural e territorial, norteado pelos interesses do mercantilismo (nas origens do capitalismo), também ele colonial, instituindo um perfil de poder eurocêntrico padronizado e hegemônico, é que surge a colonialidade do saber, atrelada à do poder.

A colonialidade do poder, para Quijano (2005), se constitui de "o outro lado" da modernidade, pois "em seu sentido moderno não tem história conhecida antes da América" (2005, p. 107). Trata-se de um sentido que nos leva a relações de poder e de dominação, cuja linha histórica retrata a permanência nas relações do capitalismo mundial contemporâneo e as desigualdades surgidas à época da colonização/império português; é por este continuum colonial que se pode entender a falta de legitimidade política de alguns países da América Latina.

Surgindo como derivação do conceito de colonialidade do poder, o conceito de colonialidade do saber remete à construção do conhecimento dentro das relações de poder. E no processo de construção dos saberes, a escola surge com um papel fundamental de padronizar e separar a 'civilização' (europeia) da 'barbárie' (sul americana).

Beatriz Gonzáles Stephan (1996 apud CASTRO-GOMÉZ, 2005), estudiosa venezuelana dos dispositivos educacionais de poder implantados na América Latina no século XIX e do reflexo desses dispositivos na constituição da "invenção do outro", aponta três métodos disciplinares que auxiliaram na formação do cidadão latinoamericano do século XIX: os manuais de urbanidade, as constituições e as gramáticas do idioma. E, este último, a unificação de regras em gramática de um idioma, passaria a servir a meios comerciais e a meios de imposição cultural, sendo fomentados no seio escolar, para a formação de cidadãos do "bem dizer" colonizador:

O projeto de construção da nação requeria a estabilização linguística para uma adequada implementação das leis e para facilitar, além do mais, as transações comerciais. (...) Da normatividade da letra, as gramáticas buscam gerar uma cultura do "bem dizer" com o fim de evitar "as práticas viciosas da fala popular" e os barbarismos grosseiros da plebe (CASTRO-GOMÉZ, 2005, p. 82)

Ambas as colonialidades - poder e saber - convergem para a problemática do que seja moderno ou subdesenvolvido, do que seja central ou periférico, do que seja 
colonizador e colonizado, ordenados, respectivamente, pela agência do poder capitalista e dos postulados do território europeu versus a barbárie do sul.

\section{5) Literatura brasileira colonial: Quinhentismo e Pero Vaz Caminha}

A colonialidade do saber remonta aos primeiros escritos na 'real língua vernácula', em que os escritores eram porta-voz dos colonizadores, em busca de status social diante da grandeza lusitana, haja vista os primeiros anos de colônia, quando a influência portuguesa ocorria de forma mais efetiva.

Desde a escrita primeira do período Quinhentista, a primeira escola literária segundo a historiografia (mesmo sem produções feitas - em registro - por nativos), temos uma visão da literatura brasileira influenciada pelo olhar estrangeiro e pela sua maneira de escrita, pois as produções desse período literário objetivavam realizar uma descrição que tematizava os nativos e a região na qual se encontraram, mas não possuíam a visão desses, ou seja, produções que falam sobre nós, mas não são feitas por nós. Não havia, na realidade produções literárias, mas sim relatos informativos dos primeiros momentos de conquista do novo território, do 'novo mundo':

\footnotetext{
Enquanto informação, não pertencem à categoria do literário, mas à pura crônica histórica e, por isso, há quem as omita por escrúpulo estético [...]. No entanto, a pré-história das nossas letras interessa como reflexo da visão do mundo e da linguagem que nos legaram os primeiros observadores do país (BOSI, 1992, p. 13).
}

Enfim, os escritos da época colonial nada mais foram do que registros feitos pelos colonizadores sobre o território brasileiro e suas riquezas com o objetivo de transcrever e informar aos reis portugueses, o que era de posse da Coroa Portuguesa; os nativos e suas culturas, aos "olhos do descobridor", seriam muito primários para cuidar do território brasileiro com seu patrimônio material e imaterial.

Como bem descreve Pero Vaz de Caminha (s/d) em sua carta informativa, considerada como primeiro texto literário do Brasil, é necessário ressaltar a supremacia portuguesa em relação ao novo território conquistado: “[...] o melhor fruto que dela se pode tirar parece-me que será salvar esta gente. E esta deve ser a principal semente que 
Vossa Alteza em ela deve lançar.” (s/d, p. 14) ${ }^{13}$. Este trecho, repetidamente reproduzido nos contextos escolares, testemunha o eurocentrismo da modernidade. "Salvar esta gente" pode ser interpretado como a retirada dos índios do atraso pelo qual os portugueses entendiam aqueles que não participavam das normas e culturas europeias. Ora, “[...] para o moderno, o bárbaro tem uma 'culpa' (por opor-se ao processo civilizador) que permite à 'Modernidade' apresentar-se não apenas como inocente, mas como 'emancipadora' dessa 'culpa' de suas próprias vítimas" (DUSSEL, 2005, p. 29).

Em outro trecho da carta, no que tange à descrição do índio, a ideia de uma raça colonizada emerge: "[índios] pardos, todos nus, sem coisa alguma que lhes cobrisse suas vergonhas" (CAMINHA, s/d, p. 2). Ou seja, a etnia indígena, cor parda da pele e sua cultura - "todos nus" - eram atípicas à cultura europeia por questões históricas e religiosas, em que a culpabilidade cristã proíbe a nudez, porquanto estar nu é vergonha, é mostrar as genitálias, ou seja, representação da vergonha.

Os dois trechos da carta de Pero Vaz de Caminha reforçam o conceito de prosperidade da Modernidade europeia; os estrangeiros nativos são os outros perante à majestosa cultura ocidental. Para uma posição crítica diante do conhecimento literário, não há como negar a presença das dicotomias que desta carta emergem: colonizador versus colonizado, centro versus periferia, dominante versus dominado.

Ainda que, na maioria dos livros didáticos - por exemplo, (1) Português contemporâneo: diálogo, reflexão e uso (CEREJA; DIAS VIANA; DAMIEN, 2016), (2) Português? Contexto, interlocução e sentido (ABAURRE; PONTARA, ABAURRE, 2008), (3) Se liga na língua: Literatura, Produção de texto, Linguagem (ORMUNDO, 2018) e (4) Português: trilhas e tramas (SETTE; TRAVALHA;STARLING, 2015) -, a literatura brasileira seja dividida entre a era colonial e a brasileira, é só a partir do Barroco que há produções escritas por autores brasileiros, mesmo que a temática ainda gire em torno de "moldes lusitanos" ou sobre a relação índio e homem branco por uma ótica europeia. Mas é, a partir do Romantismo que as obras literárias, mesmo que as temáticas sejam sobre as relações índio e homem branco, passam a retratar os temas nacionais por uma visão mais nativa.

\footnotetext{
${ }^{13}$ As edições publicadas da Carta de Pero Vaz de Caminha se encontram desde em livros didáticos até em documentos institucionais e governamentais. Por exemplo: (1) livro A carta de Pero Vaz de Caminha, Petrópolis/Rio de Janeiro: Vozes, 2015 [uso didático]; (2) apostilas de Exercício do Enem, disponível em: https://www.stoadi.com.br/intensivo2019 [uso didático]; A Biblioteca Virtual de Literatura, disponível em: https://www.biblio.com.br [o veículo utilizado neste artigo e indicado no item Referências]; Arquivo Nacional da Torre do Tombo, Lisboa, disponível em: https://www.digitarq.arquivo.pt; Carta de Caminha/EBC - Arquivo Nacional, disponível em: https://www.ebc.com.br/culura/2013.
} 


\section{6) Considerações finais}

É necessário que o ensino de literatura ocorra de forma crítica para que não haja a propagação não racionalizada do saber, em que a literatura seja uma disciplina reprodutora de um conservadorismo e de uma concepção de mundo baseados na ideia de modernidade eivada pelo eurocentrismo, configuradora de processos de dominação.

Mesmo diante da constatação de uma disseminação de saberes eurocêntricos na educação brasileira, faz-se imprescindível privilegiar o ensino da literatura latinoamericana, inclusive para além do Brasil, de modo a adequar nosso ensino ao contexto de nossa cultura, evitando o empobrecimento e reducionismo crítico da identidade local dos alunos.

Nessa construção da identidade, os alunos, enquanto cidadãos pertencentes a um continente que tem voz, se faz necessária a promoção de discussões sobre o que é a América, o que se produziu e se produz neste continente, para a efetivação de um ensino mais coerente.

Sem o objetivo de uma mudança radical nos livros didáticos e sem negar o conservadorismo que atravessa o sistema de ensino, este estudo tem como finalidade descortinar a assiduidade e a reprodução dos estudos europeus em nossa Escola e questionar a invisibilidade das produções latino-americanas nos materiais didáticos. $\mathrm{Ou}$ melhor, as práticas de ensino poderiam exigir uma reflexão contestatória, de resistência ao eurocentrismo, diante do que estamos fazendo de nosso ensino, de como estamos conduzindo e contribuindo para uma possível descolonialidade do saber, e de como reconstruir um ensino que nos inclua como território continental, não apenas como um país à parte, fora do cont(exto)inente. Ou melhor, que epistemologias de um saber crítico se estendam para além de espaços bilaterais (dominante/dominado).

\section{Referências}

ABAURRE, Maria Luíza; PONTARA, Marcela Nogueira; ABAURRE, Maria Bernadete. Português? contexto, interlocução e sentido. Volume 1, 2 e 3. São Paulo: Moderna, 2008.

AZIBEIRO, Nadir Esperança. Modernidade, colonialidade ocidental e a produção subalterna do outro. Pro-Posições, [S.1.], v. 18, n. 2, p. 89-101, fev. 2016. Disponível em: http://periodicos.sbu.unicamp.br/ojs/index.php/proposic/article/view/8643547. Acesso em 28 de ago. de 2016. 
BOURDIEU, Pierre. Homo academicus. Tradução Ione Ribeiro Valle e Nilton Valle. Santa Catarina: Editora UFSC, 2011.

BOURDIEU, Pierre; PASSERON, Jean-Claude. A reprodução. Elementos para uma teoria do sistema de ensino. Tradução Reynaldo Bairão. $3^{\text {a }}$.ed. Petrópolis/Rio de Janeiro: Vozes, 2008.

BOSI, Alfredo. Dialética da colonização. São Paulo: Cia das Letras, 1992.

BRASIL. Diário Oficial da União, Brasília, DF, 10 jan. 2003. Disponível em: http://www.planalto.gov.br/ccivil_03/leis/2003/L10.639.htm. Acesso em: 04 de set. de 2016.

BRASIL. Secretaria da Educação Básica. Base Nacional Comum Curricular. Brasília: Ministério da Educação, 2015.

CAMINHA, Pero Vaz de. Carta de Pero Vaz de Caminha.(s/d) Disponível em: http://www.biblio.com.br/defaultz.asp?link=http://www.biblio.com.br/conteudo/perovaz caminha/carta.htm. Acesso em: 07 de set. de 2016.

CANDIDO, Antonio. Formação da literatura brasileira. 7. ed. Rio de Janeiro: Itatiaia, 2000.

CASTRO-GÓMEZ, Santiago. Ciências sociais, violência epistêmica e o problema da "invenção do outro". In: LANDER, Edgardo (Org.). A colonialidade do saber eurocentrismo e ciências sociais: perspectivas latino-americanas. Buenos Aires: Clacso, 2005. p. 80-87. (Coleção Sur Sur).

CEREJA, William Roberto. Literatura brasileira: em diálogo com outras literaturas e outras linguagens. 4. ed. São Paulo: Atual, 2009.

CEREJA, William Roberto; DIAS VIANA, Carolina; DAMIEN, Christiane. Português contemporâneo: diálogo, reflexão e uso. Volume 1, 2 e 3. São Paulo: Saraiva Educação Ltda. 2016.

DUSSEL, Enrique. Europa, modernidade e eurocentrismo. In: LANDER, Edgardo (Org.). A colonialidade do saber - eurocentrismo e ciências sociais: perspectivas latinoamericanas. Buenos Aires: Clacso, 2005. p. 24-32. (Coleção Sur Sur).

EAGLETON, Terry. A ideia de cultura. $2^{a}$. ed. Tradução Sandra Castello Branco. São Paulo: Editora UNESP, 2003.

HAESBAERT, R. O mito da desterritorialização: do "fim dos territórios" à multiterritorialidade. Rio de Janeiro: Bertrand Brasil, 2004.

HOLANDA, Sérgio Buarque de. Raízes do Brasil. São Paulo: Companhia das Letras, 2013. 
LANDER, Edgardo. Ciências sociais: saberes coloniais e eurocêntricos. In:

colonialidade do saber - eurocentrismo e ciências sociais: perspectivas latinoamericanas. Buenos Aires: Clacso, 2005. p. 8-23. (Coleção Sur Sur).

ORMUNDO, Wilton. Se liga na língua: literatura, produção de texto, linguagem. São Paulo: Moderna, 2018.

QUIJANO, Aníbal. Colonialidade do poder, eurocentrismo e América Latina. In: LANDER, Edgardo (Org.). A colonialidade do saber - eurocentrismo e ciências sociais: perspectivas latino-americanas. Buenos Aires: Clacso, 2005. p. 107-130. (Coleção Sur Sur).

SANTOS, Boaventura de Sousa; MENEZES, Maria Paula. Epistemologias do sul. São Paulo: Cortez, 2011.

SANTOS, José Roberto de Souza; SIVERES, Luiz. O conhecimento como princípio da colonialidade e da solidariedade. Conjectura: filosofia e educação, Caxias do Sul, v. 18, n. 3, p. 124-137, 2013. Disponível em: http://www.ucs.br/etc/revistas/index.php/conjectura/article/viewArticle/1928. Acesso em: 29 de ago. de 2016.

SETTE, Graça et alii. Português: trilhas e tramas. Portugal: LeYa/Brasil: Casa da Palavra, 2015.

VATTIMO, Gianni. O fim da modernidade: niillismo e hermenêutica na cultura pósmoderna. Rio de Janeiro: Presença, s/d.

\title{
COLONIALITY OF KNOWLEDGE IN BASIC EDUCATION: RESISTANCE OR REPRODUCTION OF EUROCENTRISM?
}

\begin{abstract}
This paper seeks to problematize the teaching of literature in the Brazilian Basic Education system. Concepts of coloniality of knowledge and coloniality of power are foregrounded to explain how Eurocentrism is still present Brazilian School discourses, regarding the possibility of resistance to colonizers or not. As such, this investigation engages with education theorists and decolonial thinking.
\end{abstract}

\section{Keywords}

Coloniality of knowledge and power. Reproduction or resistance. Teaching. Literature. 